\title{
Erratum: Chromatic properties of astigmatic eyes
}

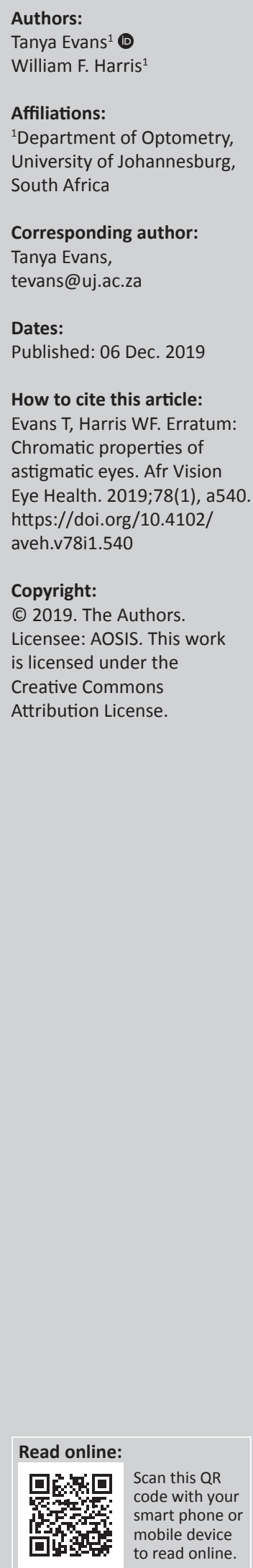

In the author list of this article published earlier, Tanya Evans' ORCID was unintentionally misprinted as https://orcid.org/0000-0002-5503-0245. The correct ORCID for Tanya Evans is https:/ / orcid.org/0000-0001-8307-2912. The publisher sincerely regrets this error and apologises for any inconvenience caused. 